\title{
Un nuevo caso de histiocitoma fibroso maligno dependiente de cápsula renal
}

\section{A new case of malignant fibrous histiocytoma arising from the renal capsule}

\section{Sr. Director:}

El motivo de esta carta es aportar un nuevo caso de histiocitoma fibroso maligno dependiente de cápsula renal.

Versa sobre una mujer de 68 años con antecedentes personales de hipertensión arterial, en tratamiento los últimos meses con hierro oral y ácido fólico por anemia ferropénica actualmente resuelta, y una prima intervenida hace 6 meses de tumor renal (hipernefroma) a los 60 años.

Desde enero de 2009 refiere dolor en el hipocondrio izquierdo, sin otros antecedentes urológicos. La analítica no presenta alteraciones: creatinina $1,14 \mathrm{mg} / \mathrm{dl}$, hematocrito $39,3 \%$ y hemoglobina $13,5 \mathrm{~g} / \mathrm{dl}$.

La exploración física resultó sin anormalidades, salvo la palpación de un aumento de consistencia en la fosa renal izquierda, por lo que se inicia un estudio por imagen con radiografía abdominal, que revela un voluminoso aumento de densidad con efecto masa en el hemiabdomen izquierdo. En la ecografía se observa una masa renal izquierda de aproximadamente $14 \mathrm{~cm}$ de diámetro y la tomografía axial computarizada (TAC) abdómino-pélvica con contraste intravenoso pone de manifiesto una voluminosa masa quística con tabicaciones finas y groseras, que ocupa la parte posterior

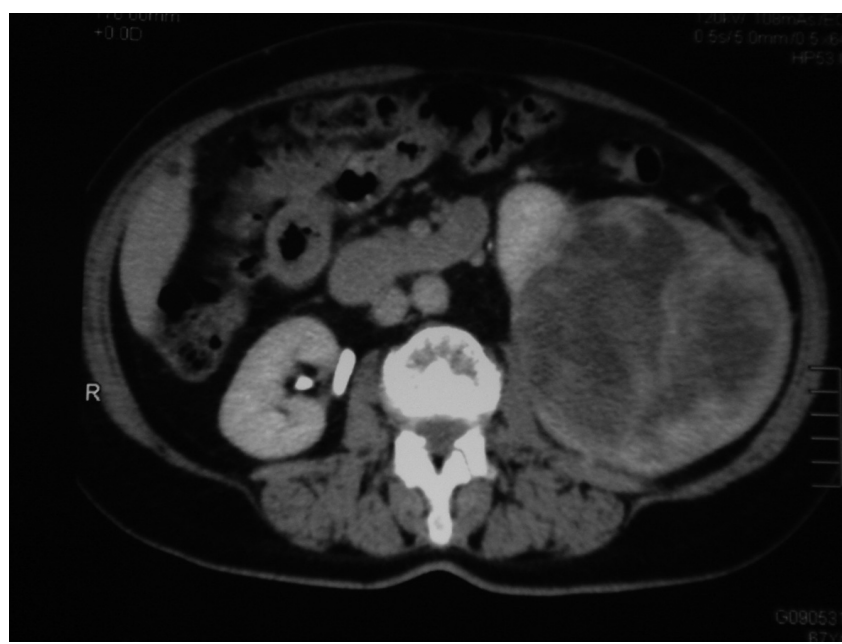

Figura 1 - Imagen de tomografía axial computarizada abdominopélvica con contraste, donde se aprecia una voluminosa masa quística con tabicaciones finas y groseras y polos sólidos parietales y en declive, que ocupa la parte posterior del riñón izquierdo con extensión a la cápsula, con unas medidas aproximadas de $12 \times 10 \times 7,9 \mathrm{~cm}$, sugestiva de hipernefroma quístico. del riñón izquierdo con extensión a cápsula, de aproximadamente 12 x $10 \times 7,9 \mathrm{~cm}$, sugestiva de hipernefroma quístico. Sin adenomegalias; la suprarrenal izquierda se encuentra desplazada hacia arriba sin patología. En el resto de la exploración no se observan alteraciones (fig. 1).

Bajo el diagnóstico de tumor renal izquierdo se decide intervenir a la paciente en el mes de febrero, practicando una exéresis completa de la masa mediante nefrectomía radical izquierda laparoscópica, sin signos aparentes de extracapsularidad.

El postoperatorio transcurre sin indicendias.

La pieza enviada a anatomía patológica es de un peso de $1.689 \mathrm{~g}$, con presencia en la convexidad renal de una masa tumoral lobulada y aparentemente bien encapsulada de $15 \mathrm{x}$ $14 \times 12 \mathrm{~cm}$, de corte uniforme, amarillenta, de superficie lisa y consistencia blando-elástica.

Macroscópicamente no depende del parénquima renal, salvo en una zona aproximadamente de $1 \mathrm{~cm}$ donde parénquima renal, cápsula y tumor extracapsular se encuentran íntimamente unidos.

Microscópicamente es un tumor mesodérmico con áreas de celularidad densa de patrón fibro-histio, marcado pleomorfismo y frecuentes células gigantes, con otras de dominante patrón mixoide de estroma laxo y celularidad menos abigarrada. Hay una clara relación del tumor con la cápsula renal, siendo en estas áreas donde se ven células de citoplasma vacuolado, identificables como lipoblastos, dominando el patrón pleomórfico fibro-histio-mixoide. El perfil inmunohistoquímico es positivo para vimentina, CD68 y Ki67 (en un 20\% de las células, equivalente a un bajo índice de proliferación) (fig. 2).

Todo ello orienta al diagnóstico de sarcoma pleomórfico retroperitoneal en relación con la cápsula renal. Se completó el estudio por FISH en búsqueda de presencia de amplificación de MDM2, habitual en liposarcomas desdiferenciados, liposarcomas esclerosantes o similares al lipoma, evidenciándose la ausencia de dicha amplificación, lo cual descartaba que este sarcoma de alto grado fuese un liposarcoma.

Así, a la vista de los resultados, el diagnóstico para este tumor es de sarcoma pleomórfico indiferenciado compatible con histiocitoma fibroso maligno pleomórfico.

Se administró tratamiento quimioterápico adyuvante con adriamicina $75 \mathrm{mg}$ durante tres semanas.

La TAC toraco-abdómino-pélvica de control no presenta signos de recidiva local o a distancia.

En cuanto al sarcoma renal primario, es un tumor raro que representa el 3\% de todos los tumores renales malignos. 
El histiocitoma fibroso maligno es el más frecuente de los sarcomas (0,2-0,6\% y más comúnmente localizado en tejidos blandos de extremidades) presentes en la edad adulta, siendo muy raros en la infancia. En un $12-15 \%$ se encuentran en el retroperitoneo, siendo excepcional su origen a partir de cápsula renal o de componentes tisulares del hilo renal.

Existen diferentes hipótesis sobre su origen, unas orientadas a que deriva de histiocitos y otras de células mesenquimales pluripotenciales.

Su clasificación se basa en el análisis microscópico, etiquetándolos en diversas variantes:

1. Fibrosos de células gigantes: a) estoriforme o "en rueda de carro"; b) pleomórfico (el más frecuente dentro de este grupo); y c) fascicular.

2. Inflamatorio.

3. Mixoide (el más frecuente y el de mejor pronóstico).

La clínica depende del tamaño del tumor, siendo muy inespecífica, pudiendo alcanzar gran tamaño por su ubicación retroperitoneal antes de provocar síntomas, retrasando el diagnóstico precoz de la enfermedad.

No obstante, el síntoma más frecuente es dolor en la fosa renal afecta, acompañado de síndrome constitucional de varios meses de evolución.

El diagnóstico inicial se realiza por medio de pruebas de imagen que permiten orientar sobre la composición, densidad, extensión y relación con órganos y estructuras adyacentes, mostrando desplazamientos del riñón, del uréter o la vejiga con relación al tumor.

Aunque el histiocitoma fibroso maligno es indistinguible tanto clínica como radiológicamente del carcinoma renal, se debe pensar en él ante determinadas características radiológicas: a) tumores mayores de $10 \mathrm{~cm}$ al diagnóstico y que no invaden ni el parénquima renal ni la vena cava o renal; b) los tumores tienen señales de varias intensidades en las imágenes de resonancia, áreas hipodensas en T1 y T2 reflejando los componentes fibrosos, mientras las áreas hipodensas en T1 e hiperdensas en T2 reflejan degeneración cística, necrosis o regiones ricas en células histiocíticas; c) tumores hipovasculares o avasculares en las angiografías; y d) presencia de áreas hipodensas correspondientes a degeneración cística multilocular y áreas hiperdensas correspondientes a calcificaciones en imágenes de TAC.

El diagnóstico definitivo nos lo proporcionará la anatomía patológica. En cuanto al aspecto macroscópico son tumores grandes, multilobulados, de coloración amarillogrisácea, que presentan áreas hemorrágicas con necrosis en su interior.

Microscópicamente están constituidos por un amplio pleomorfismo conformado por células fibroblásticas e histiocitos. Inmunohistoquímicamente presentan positividad para CD68 y quimiotripsina.

El único tratamiento con intención curativa es la extirpación completa de la pieza, requiriendo en ocasiones ser extensivos a órganos adyacentes para garantizar la radicalidad del acto quirúrgico. La vía de abordaje depende de la localización, características y extensión del tumor.

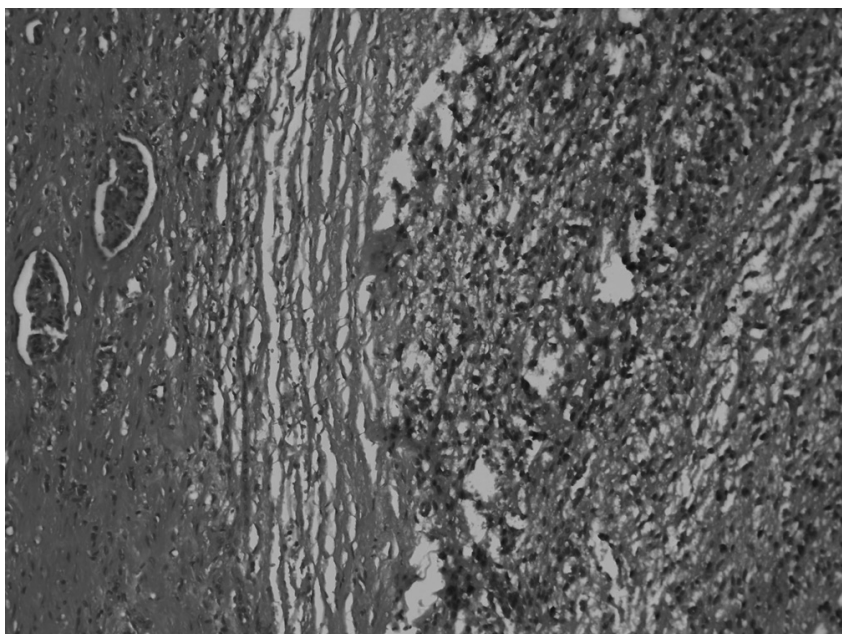

Figura 2 - Visión microscópica de sarcoma pleomórfico indiferenciado, compatible con histiocitoma fibroso maligno pleomórfico dependiente de cápsula renal, visualizándose aisladamente parénquima, cápsula renal y tumor.

Generalmente son de mal pronóstico con una tasa de supervivencia del $60 \%$ a los dos años, y de recurrencia entre el 50 y el $82 \%$. Los órganos más frecuentemente metastatizados son el pulmón (más frecuentemente), hígado, hueso y médula ósea.

Es controvertido el tratamiento complementario con radioterapia y quimioterapia, no habiendo sido observado un aumento global de la supervivencia en estos pacientes.

En cuanto al tratamiento quimioterápico, el fármaco que constituye la base del mismo es adriamicina asociada a DTIC (dimetil-triazeno-imidazol-carbosamida) o a vincristina.

\section{B I B L I O G R A F Í A R E C O M E N D A D A}

Argüelles Salido E, Congregado Ruiz CB, Medina López MA, Pascual del Pobil Moreno JL. Histiocitoma maligno fibroso retroperitoneal. Actas Urol Esp. 2004;28(8):624-6.

Eroğlu M, Bakirtaş H, Cimentepe E, Unsal A, Ataoğlu O, Balbay MD. Malignant fibrous histiocytoma arising from the renal capsule. Urol Int. 2005;75(4):368-70.

Gabbert H, Wagner R, Becht E. Malignant fibrous histiocytoma of the renal capsule. J Cancer Res Clin Oncol. 1981;100(3): 285-93.

Gimeno Argente V, Bosquet Sanz M, Gómez Pérez L, Delgado Oliva FJ, Arlandis Guzmán S, Jiménez Cruz JF. Histiocitoma fibroso maligno retroperitoneal con infiltración de órganos vecinos. Actas Urol Esp. 2007;31(5):562-6.

Gupta R, Gupta S, Aggarwal D, Singh S. Primary pleomorphic undifferentiated sarcoma of the kidney: a rare renal tumor. Indian J Pathol Microbiol. 2008;51(4):574-5.

Gutiérrez Mínguez E, Arroyo Muñoz JL, Espiga Santamaría J. Malignant fibrohistiocytoma of the renal capsule. Report of a case and review of the literature. Actas Urol Esp. 1996;20(8):744-5.

Kanno T, Kamoto T, Terai A, Kakehi Y, Terachi T, Ogawa O. A case of malignant fibrous histiocytoma arising from the renal capsule. Hinyokika Kiyo. 2001;47(2):95-8. 
Kitajima K, Kaji Y, Morita M, Okuda Y, Sugimura K. Malignant fibrous histiocytoma arising from the renal capsule. Magn Reson Med Sci. 2004;4(2):199-202.

López JI, Angulo JC, Flores N, Toledo JD. Malignant fibrous histiocytma of the renal capsule and synchronous transitional cell carcinoma of the bladder. Pathol Res Pract. 1996;192(5):468-73.

Matsui Y, Kobayashi S, Sugino Y, Iwamura H, Oka H, Fukuzawa $\mathrm{S}$, et al. Malignant fibrous histiocytoma originating in a renal capsule: a case report. Hinyokika Kiyo. 2001;47(10):727-9.
R. Sierra Labarta*, M.J. Gil Sanz, G. Muñoz González y L.A. Rioja Sanz Servicio de Urología, Hospital Universitario Miguel Servet, Zaragoza, España

${ }^{*}$ Autor para correspondencia. Correo electrónico. carrocar80@hotmail.com (R. Sierra Labarta) 